\title{
QUANTITATIVE NUCLEAR VARIATION IN INBRED LINES AND HYBRID RYE
}

\author{
D. J. KIRK* and R. N. JONES \\ Deportment of Agricultural Botany, University College of Woles, Aberystwyth, U.K. \\ Received 18.vi.73
}

\section{SUMMARY}

Quantitative effects of inbreeding depression and heterosis in rye have been analysed at three levels of organisation: (i) the plant, (ii) the cell and (iii) the nucleus.

(i) Hybrid plants have a higher mean fresh weight than the inbred lines over the first few weeks of growth. This is accounted for by a faster rate of growth and also by some initial advantages in seed weight.

(ii) There is a difference in the cellular organisation of root meristems. Hybrids have almost twice as many cells per unit fresh weight as inbred lines.

(iii) At the nuclear level, in root meristem nuclei, hybrids have greater amounts of total protein and RNA and smaller amounts of histone than do the inbred lines.

\section{INTRODUGTION}

Cultivated rye Secale cereale $\mathrm{L}$. is naturally an outbreeding species. Inbreeding by forced self-fertilisation results in a loss of vigour and fertility. Crosses between divergent inbred lines leads to hybrid vigour in $F_{1}$ plants.

Detailed studies of the effects of inbreeding depression on morphological characters of rye have been made by Sybenga (1958). He observed strong effects on most of the nine quantitative characters under study, which included the number of tillers per plant, diameter of the stem, final plant weight and height.

At the nuclear level, cytological studies of inbred rye were initiated by Lamm (1936). He found inbred lines to have pronounced meiotic disturbances, including such effects as lower chiasma frequencies than in corresponding population rye. This work was elaborated further by Müntzing and Akdik (1948) and by Rees (1955a, b) who also elucidated the genetic basis for the abnormal chromosome behaviour.

The present work is mainly concerned with chemical and physiological changes in the nucleus in an attempt to define the specific differences that occur and in order to arrive at a better understanding of the way in which heterozygous combinations of genes act to produce their effects. The investigation is cytochemical, using specific staining reactions with isolated root meristem nuclei for quantitative estimations of total nuclear protein, nuclear RNA and histone protein. An attempt is also made to correlate nuclear phenotypic variation with changes at the level of the cell and of the whole plant. It is for this reason that data are first presented for the growth characteristics of inbred lines and hybrids over the first few weeks of growth.

* Present address: Galton Laboratory, University College London, London NWI $2 \mathrm{HE}$. 


\section{Materials and methods}

(A) Material

The rye material used in the present study is Secale cereale, $2 n=2 x=14$. The inbred lines used $\left(\mathrm{P}_{1}, \mathrm{P}_{8}, \mathrm{P}_{12}, \mathrm{P}_{13}\right)$ are all derived from the Swedish variety Stalrag by Professor Müntzing at Lund. $\mathrm{P}_{1}, \mathrm{P}_{12}$ and $\mathrm{P}_{13}$ derive from population plants inbred in 1926, and have been maintained by continuous self-pollination ever since. They have a history of inbreeding therefore that goes back for over 40 years. $P_{1}$ was started from a population plant grown in 1928. Details of the breeding programme are given by Rees $(1955 b)$.

$F_{1}$ hybrid seed, obtained from crosses between the appropriate pairs of inbred lines, tends to be rather poor due to the influence of its maternal parent. $\mathrm{F}_{2}$ seed are larger and more vigorous, since they result from the crossing of pairs of vigorous $F_{1}$ plants. For these reasons $F_{2}$ seeds were used for comparisons with the inbred parents.

\section{(B) Methods}

\section{(i) Growing the plants}

Seeds were germinated and grown for 2-3 days on moist filter paper before subsequent transfer to culture bowls containing 9 litres of Pierce's (1937) complete nutrient solution. The culture bowls were kept at room temperature and subjected to a photoperiod of 14 hours. They were aerated for 1 hour daily to ensure complete circulation of nutrients and oxygen. This method of growing the plants gave an abundant supply of actively growing clean roots, and for any one experiment plants from different lines could be grown together in the same bowl and thus receive uniform treatment as far as mineral nutrition, $p \mathrm{H}$, temperature and water supply were concerned.

\section{(ii) Measurement of growth rates}

Growth rates of the different genotypes were assessed from fresh weight measurements on seedlings growing in culture, as outlined above. Total fresh weight determinations were made at 2-3 day intervals by carefully removing plants from the culture bowl, blotting the roots and weighing the whole plant. Average plant fresh weights were determined from bulk weighings of 10 plants at a time. The assessment of the growth potential of inbred lines and hybrids refers therefore to young plants over the first 9 weeks of growth.

\section{(iii) Estimation of cell number per $\mathrm{mg}$ fresh weight of root meristem}

The method of determining cell numbers was a modification of that given by Setterfield, Schreiber and Woodward (1954). Meristematic root tips $3 \mathrm{~mm}$ in length were excised, accurately weighed and fixed in 1:3 acetic alcohol for 30 minutes. They were then hydrolysed in $1 \mathcal{N}$ $\mathrm{HCl}$ at $60^{\circ} \mathrm{C}$. for 12 minutes before staining in Feulgen's solution for 30 minutes. After washing, the root tips were left overnight, each in $0.5 \mathrm{ml}$ of a 5 per cent pectinase solution in $0.01 \mathrm{M}$ Tris $\mathrm{HCl} p \mathrm{H} 4.0$, in individual specimen tubes at $25^{\circ} \mathrm{C}$. The following morning each tip was carefully transferred to $0.5 \mathrm{ml}$ of $0.01 \mathrm{M}$ acetate buffer $p \mathrm{H} 4.0$ in a micro-centrifuge 
tube and shaken violently for 5 minutes on a "Whirlimixer". This treatment produced a complete separation of the cells and at the same time left them individually intact. Cell number counts were them made using a haemacytometer counting chamber.

\section{(iv) Isolation of nuclei}

Photometric estimations of total nuclear protein, nuclear RNA and nuclear histones were performed on isolated meristematic root tip nuclei (at interphase) adhering to glass slides. The technique for isolating the nuclei is based on the method of McLeish (1963), with modifications devised by Evans (1968) and the authors. Root tips from rye plants grown in the culture solution were placed in $\mathrm{M} / 30$ ice-cold phosphate buffer containing 4.0 per cent formaldehyde for 10 minutes. The terminal $0-1 \mathrm{~mm}$ of the root tips was then tapped out on a pre-cooled glass slide in a drop of the phosphate buffer solution. Excess debris was removed and a coverslip applied. The slides were allowed to dry out slightly for 10-15 minutes and the cover glass then floated off by inverting the slides in the formaldehyde solution, in which they were allowed to stand for a further 30 minutes to complete fixation. Enough nuclei adhere to the slides after washing for the staining schedules detailed below to be carried out.

\section{(v) Staining for total nuclear protein with $2: 4$ dinitrofluorobenzene}

The method is given by Mitchell (1967). $2: 4$ Dinitrofluorobenzene (DNFB) stains the protein by forming a yellow complex with the free- $\mathrm{NH}_{2}$ groups of proteins, the $\epsilon$-group of lysine, the phenolic-OH of tyrosine, and the imadazole group of histidine and gives a quantitative assessment of total protein. The yellow stain has a maximum absorption peak at $400 \mathrm{~m} \mu$. After dehydration in absolute alcohol, the slides were stained by immersing in DNFB stain for 12 hours at $65^{\circ} \mathrm{C}$. Staining was followed by a wash in absolute alcohol and the coverslips applied over a drop of glycerol.

\section{(vi) Staining for nuclear $R \mathcal{N} A$ with methyl-green and pyronin- $\Upsilon$}

Methyl-green stains highly polymerised DNA. Rosenkrantz and Bendich (1958) have shown that binding of methyl-green is dependent only on the presence of the double helix and is independent of chain length. Pyronin-Y binds specifically to the lower polymer RNA. Denatured DNA, due to exposure to acids, u.v. irradiation etc., can be bound by pyronin-Y, but it is unlikely that this would have happened under the mild conditions used in the present experiments. The staining procedure is that given by Moss (1967). Slides were immersed in the stain for 15 minutes, rinsed in water, immersed in a differentiating solution of tertiary butyl alcohol and absolute alcohol $(3: 1)$ for 10 minutes, cleared in xylene and finally mounted in a drop of glycerol. Absorption was measured at a wavelength of $550 \mathrm{~m} \mu$. The specificity of pyronin-Y for RNA was checked using a ribonuclease. Two sample slides of nuclei were treated with a $0 \cdot 1$ per cent $(w / v)$ RNA-ase solution (type 1-A Sigma, London) at $40^{\circ} \mathrm{C}$. (Moss, loc. cit.) for $1 \frac{1}{2}$ hours. The DNA stains green and the RNA (a major constituent of the nucleolus) stains a reddish pink. In the RNA-ase control, in comparison with RNA-ase free slides, the nucleoplasm appeared a fainter green and the nucleolus was noticeably lacking in its reddish-pink coloration. 


\section{(vii) Staining for histones with fast green FCF}

A selective staining method for the basic chromosomal proteins (histones) has been reported by Alfert and Geschwind (1953). The conditions essential for histone staining and specificity are removal of DNA and high basicity of the staining solution. Histones have an isoelectric point which is much more alkaline $(p \mathrm{H} \mathrm{10-11)}$ than other proteins. At $p \mathrm{H} \mathrm{8 \cdot 0-8 \cdot 1} \mathrm{most} \mathrm{proteins} \mathrm{are} \mathrm{near}$ or above their isoelectric points whereas the histones are well below. By staining nuclei at $p \mathrm{H} 8 \cdot 0-8 \cdot 1$ in an acid dye such as fast green only the histone protein will bind the dye. As the $p \mathrm{H}$ increases above $8 \cdot 1$ the staining decreases, and at $p \mathrm{H}$ 's below 8.0 nuclear specificity is lost (Bloch, 1966). Since the publication of Alfert and Geschwind's authoritative paper, the fast green staining reaction has found increasing favour for quantitative cytochemical estimations of histone amounts (Bhattacharya, Naylor and Shaw, 1965; Himes, 1967; Miksche, 1968; Kirk and Jones, 1970; Kusanagi and Yanagi, 1970; Ayonoadu and Rees, 1971; Diez and Cionini, 1971; Innocenti, 1971; Moore, 1971). There are in addition some instances where a good agreement has been found for variation in histone amounts determined both by cytochemical means and by biochemical methods (John and Jones, 1970; Kirk, 1972).

Details of the staining schedule are as follows:

(a) The nucleic acids were removed (rendering the original histoneDNA bonds available as histone-fast green anion bonds) by treating the isolated nuclei in a 5.0 per cent $(w / v)$ solution of TCA (Trichloroacetic acid) in a water bath at $70^{\circ}-75^{\circ} \mathrm{C}$. for 25 minutes. (A Feulgen test verified that the DNA had been removed.)

(b) The TCA was washed out by three 10-minute changes in 70 per cent ethanol.

(c) Nuclei were stained for 30 minutes in a $0 \cdot 1$ per cent $(w / v)$ aqueous solution of the acid dye fast green FCF (National Aniline Division, 96 per cent dye content) adjusted to $p \mathrm{H} 8 \cdot 0-8 \cdot 1$ with a minimum of $\mathrm{N} / 10 \mathrm{NaOH}$. To steady the $p \mathrm{H}$ throughout the period a large volume of stain was used in a tall beaker. This protected the slides from $p \mathrm{H}$ fluctuations due to $\mathrm{CO}_{2}$ absorption by the stain.

(d) The slides were washed for 10 minutes in distilled water, dehydrated in 95 per cent ethanol for 2 minutes, dehydrated in absolute alcohol for 2 minutes and mounted in a drop of glycerol. Light absorption was measured at $645 \mathrm{~m} \mu$.

\section{Results}

(i) The plant-growth characteristics of lines and hybrids

Variations in the nuclear phenotype of inbred and hybrid rye is the main subject of the present investigation. These variations are themselves interesting and significant, but the more so when they can be correlated with changes at the cellular and whole plant level. It is for this reason that some account of the growth characteristics of certain lines and their hybrids is first presented.

Three inbred lines $\mathrm{P}_{1}, \mathrm{P}_{12}$ and $\mathrm{P}_{13}$ together with the $\mathrm{F}_{2}$ hybrids $\mathrm{P}_{1} \times \mathrm{P}_{13}$, $P_{12} \times P_{13}$ were used for the experiments. All the plants, inbred lines and hybrids, were grown in one culture bowl, and fresh weight determinations 
carried out according to the scheme outlined in Materials and methods using whole plants. Weighings based on an average of eight plants per line were made at intervals (see figs. 1 and 2) from day zero, just before germination, up until the plants were 63 days old. For the purposes of analysis these fresh weight data were transformed to logs, and are presented in this form in figs. 1 and 2. The logarithmic transformation of the data results in a straight plot of the log fresh weight against time for the exponential phase of the growth curves. Individual regressions of the log data for three inbred lines and the two $\mathrm{F}_{2}$ hybrids have been carried out using figures for the period 3-28 days (inclusive) only. Thus the initial mean " dry" weight of the seed and the log of fresh weight values extending beyond the exponential phase of the growth curve (taken as ending at day 28 in all cases) have been omitted from the analysis.

Individual regression for the lines and hybrids are all linear and highly significant, $\mathrm{P}<0.001$, confirming that growth is exponential over the first few weeks in all cases. A joint regression is also highly significant, but reveals in addition a considerable heterogeneity of means and regressions. Clearly there are differences between some of the lines, or between some lines and hybrids, or even between hybrids themselves in the absolute amount of growth made over the period 3-28 days. These differences, where they do exist, are likely to result from either one or a combination of two causes. These are, firstly, difference in the rate of growth, reflected by variation in the slope of the regression lines, and secondly, differences in the "starting point", as determined by the intercepts of the regression lines on the y-axis. Detailed analysis (D-tests) of differences between all meaningful pairwise combinations of lines and hybrids, for means, slopes of regression lines, and intercepts of the $y$-axis, are given in table 1 .

Means. Heterosis for fresh weights is confirmed for both the $\mathrm{F}_{2}$ hybrids, $\mathrm{P}_{1} \times \mathrm{P}_{13}$ and $\mathrm{P}_{12} \times \mathrm{P}_{13}$. In both cases the absolute amount of growth made over the period 3-28 days is significantly higher than in either of the inbred parental lines $\mathrm{P}_{1}, \mathrm{P}_{13}$ and $\mathrm{P}_{12}, \mathrm{P}_{13}$ respectively. The hybrids themselves, which have one parent in common $\left(\mathrm{P}_{13}\right)$, do not differ significantly, but certain of the inbred lines do show significant variation. $\mathrm{P}_{13}$ has a lower mean weight than either $\mathrm{P}_{1}$ or $\mathrm{P}_{12}$.

Rates of growth (b-values). As already mentioned, one way in which the differences in means may be achieved is through variations in the rate at which the plants grow. That such variations in the rate of growth are indeed implicated, emerges again from the analysis in table 1 . The situation is not quite so straightforward however, as in the case of means. For example, the hybrid $\mathrm{P}_{1} \times \mathrm{P}_{13}$ has a significantly higher rate of growth than one of the parental types, $\mathrm{P}_{13}$, but this is not so in the case of the other parent, $\mathrm{P}_{1}$ although the hybrid still has the higher $b$ value. Likewise, in the case of $\mathrm{P}_{12} \times \mathrm{P}_{13}$, the hybrids has a significantly higher rate of growth than one of the parents only, viz. $\mathrm{P}_{13}$. There are also significant differences in the rates of growth between certain of the inbred lines themselves. Notably $\mathrm{P}_{13}$ is again lower than either $\mathrm{P}_{1}$ or $\mathrm{P}_{12}$.

Intercepts of the $y$-axis. Not all of the differences between mean values can be accounted for by differences in growth rates alone. As table 1 clearly shows, the "starting points" for the regression lines all differ significantly from one another, with the exception of $\mathrm{P}_{1} / \mathrm{P}_{12}$ and the two hybrids $\mathrm{P}_{1} \times \mathrm{P}_{13} / \mathrm{P}_{12} \times \mathrm{P}_{13}$. Heterosis for fresh weights in the two hybrids is evidently 


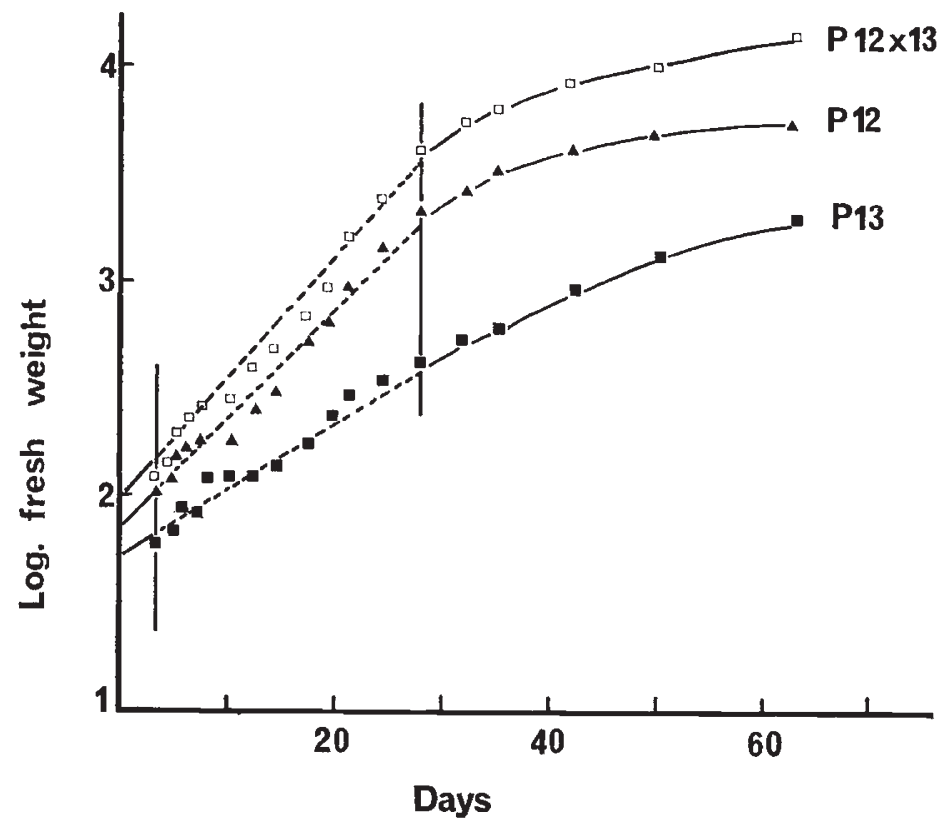

Fig. 1.-Mean fresh weight per plant in grams $(\times 1000$ and transformed to logs $)$ of inbred lines $P_{12} \Delta-\Delta, P_{18}-i$ and their $F_{2}$ hybrid $P_{18} \times P_{13} \square-\square$, plotted against time (days).

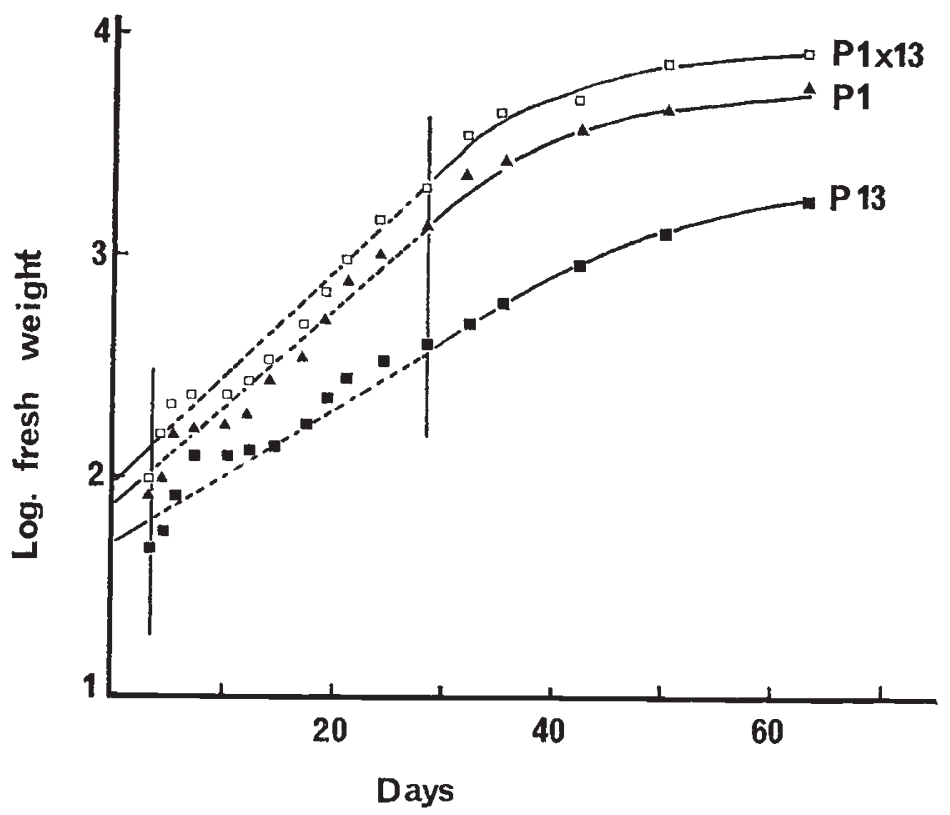

Fig. 2.-Mean fresh weight per plant in grams ( $\times 1000$ and transformed to logs) of the inbred lines $P_{1} \Delta-\Delta, P_{13}-a$ and their $F_{2}$ hybrid $P_{1} \times P_{13} \square-\square$, plotted against time (days). 
due in part to a superior start to their growth. The causes of this initial advantage are, however, difficult to ascertain. They may be due to differences in the size of seeds (and these certainly exist), size of embryos, or even variations in the rates of growth over the first few days. What is clear, is that whatever the cause or causes may be, the initial differences do exist,

\section{TABLE 1}

Detailed analyses (D-tests) of differences between means of regressions, slopes of regressions and intercepts of regression lines on the $y$-axis, for the fresh weight data $(\times 1000$ and transformed to logs)

(a) The data

$\begin{array}{lccc} & \text { Mean } & \text { Slope }(b) & \text { Intercept of } y \\ \mathrm{P}_{1} & 2 \cdot 528 & 0.055 & 3 \cdot 252 \\ \mathrm{P}_{12} & 2 \cdot 524 & 0.051 & 3 \cdot 184 \\ \mathrm{P}_{13} & 2 \cdot 152 & 0.031 & 2 \cdot 558 \\ \mathrm{P}_{1} \times \mathrm{P}_{13} & 2 \cdot 656 & 0.056 & 3.388 \\ \mathrm{P}_{12} \times \mathrm{P}_{13} & 2 \cdot 679 & 0.058 & 3.435\end{array}$

$\begin{array}{lccc}\text { (b) The analysis } & & & \\ \quad \text { Comparisons } & \text { Mean } & \text { Slo e }(b) & \text { Intercept of y } \\ \mathrm{P}_{1} / \mathbf{P}_{12} & \text { n.s. } & \text { n.s. } & \text { n.s. } \\ \mathbf{P}_{1} / \mathbf{P}_{13} & <0.01 & <0.01 & <0.01 \\ \mathbf{P}_{1} / \mathbf{P}_{1} \times \mathrm{P}_{13} & <0.01 & <0.01 & <0.01 \\ \mathbf{P}_{12} / \mathbf{P}_{13} & <0.01 & <0.01 & <0.01 \\ \mathbf{P}_{12} / \mathbf{P}_{12} \times \mathrm{P}_{13} & <0.01 & \text { n.s. } & <0.01 \\ \mathbf{P}_{13} \times \mathbf{P}_{1} \times \mathbf{P}_{13} & <0.01 & <0.01 & <0.01 \\ \mathbf{P}_{13} / \mathbf{P}_{12} \times \mathbf{P}_{13} & <0.01 & <0.01 & <0.01 \\ \mathbf{P}_{1} \times \mathrm{P}_{13} / \mathbf{P}_{12} \times \mathbf{P}_{13} & \text { n.s. } & \text { n.s. } & \text { n.s. }\end{array}$

and do make a contribution to the established variations in mean fresh weight over the first 4 weeks of growth.

\section{(ii) The cell-cell number per $\mathrm{mg}$ fresh weight}

Inbreeding depression and hybrid vigour in rye can be readily observed in such characters as height, tiller number and final plant weight. That these differences are continually developing throughout the life-cycle, and that they are indeed present even at the very early stages of seedling growth is evident from the fresh weight data presented in the previous section.

At the cellular level these differences must originate from either one, or more likely, a combination of two related processes. These processes are the rate of cell division, leading to differences in cell number, and variations in the size of cells. One way of gaining some information about these processes is simply to estimate the number of cells present per mg of fresh weight in a particular tissue.

In the experiment to be described the same material was used as that already detailed for the fresh weight growth analysis. The inbred lines were $\mathrm{P}_{1}, \mathrm{P}_{12}, \mathrm{P}_{13}$, and the hybrid $\mathrm{P}_{1} \times \mathrm{P}_{13}$ and $\mathrm{P}_{12} \times \mathrm{P}_{13} . \mathrm{F}_{2}$ plants were again used as a source of hybrid material. All plants, inbred and hybrids, were grown together under uniform conditions in one culture bowl. Cell number estimates were made on 3-mm segments of root meristems, according to the scheme outlined in Materials and methods. Root meristems in 39-day-old plants were used for the cell numbers counts. Sizeable differences 
in fresh weight are beginning to appear by this stage of growth and the plants are still producing actively growing root meristems. Five replicates were used for each of the lines and hybrids, except for $\mathrm{P}_{18}$, for which only one sample was available. Each replicate represents a single root from a different plant, and within each root there were four separate haemacytometer counts made. The results are summarised in the form of a histogram in fig. 3.

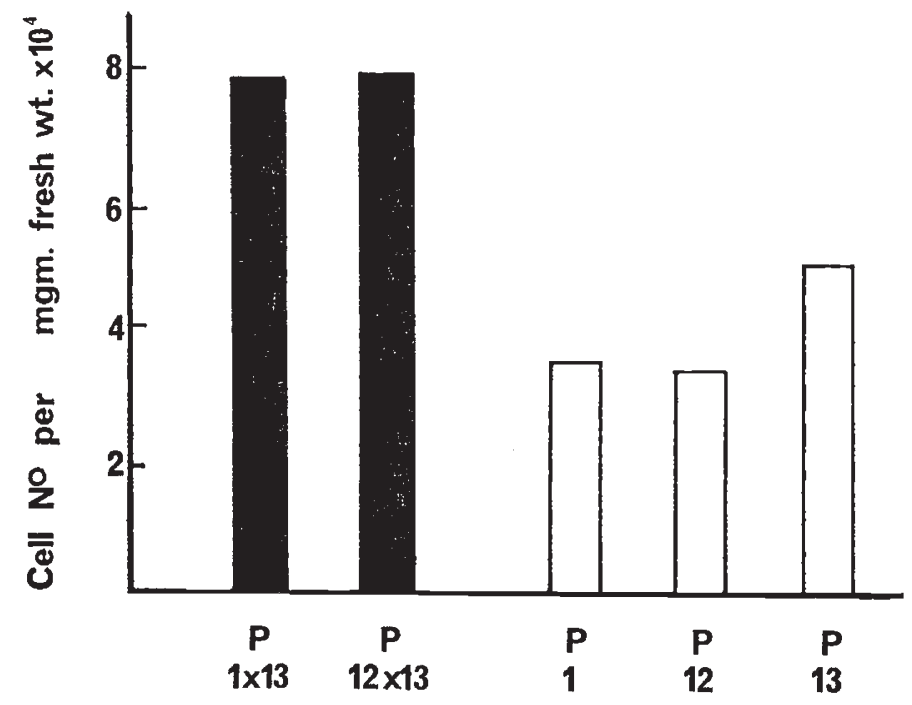

Fig. 3.-Cell number per $m g$ fresh weight of root meristem tissue in the inbred lines $P_{1}, P_{12}$, $P_{13}$ and their $F_{2}$ hybrids $P_{1} \times P_{1 s}$ and $P_{12} \times P_{1 s}$ at 39 days old.

TABLE 2

Detailed comparisons (D-tests) of differences in mean cell number per $\mathrm{mg}$ fresh weight

Comparison

$\mathbf{P}_{1} / \mathbf{P}_{12}$

$\mathbf{P}_{1} / \mathbf{P}_{18}$

$\mathbf{P}_{1} \mathbf{P}_{1} \times \mathbf{P}_{13}$

$\mathrm{P}_{12} / \mathrm{P}_{18}$

$\mathbf{P}_{12} / \mathbf{P}_{12} \times \mathbf{P}_{13}$

$\mathbf{P}_{18} / \mathbf{P}_{1} \times \mathbf{P}_{18}$

$\mathbf{P}_{18} / \mathbf{P}_{12} \times \mathbf{P}_{13}$

$\mathbf{P}_{1} \times \mathbf{P}_{18} / \mathbf{P}_{12} \times \mathbf{P}_{13}$
Probability

n.s.

n.s.

0.05

n.s.

$0 \cdot 05$

n.s.

n.s.

n.s.

The most striking feature of these results is the large difference in mean cell number per $\mathrm{mg}$ fresh weight, between the inbred lines and hybrids. In the case of $\mathrm{P}_{12} \times \mathrm{P}_{13}$ the hybrid has more than twice as many cells per unit fresh weight as either of the parental inbred lines. Likewise for $P_{1} \times P_{13}$, although in the case of $P_{13}$ the data are less reliable due to lack of replication. An analysis of variance confirms that there are significant differences between the means $(P<0.01)$. Individual $D$-tests, table 2 , show that these significant differences occur between hybrids and one of their inbred parents, viz. $P_{1}$ and $P_{12}$, for the hybrids $P_{1} \times P_{13}$ and $P_{12} \times P_{13}$ respectively. Significance was not obtained for $P_{13}$ in comparison with either of the two hybrids, 
for which it is a common parent. The reasons for this are probably twofold-firstly the low number of replicates for $P_{13}$, which is taken account of in the D-test comparisons, and secondly the fact that the error of the variance is probably augmented by variations between replicates, in the hybrids, due to some segregation of genes controlling the processes of cell multiplication and cell growth. Glearly the established heterosis for whole plant growth in rye, confirmed in the previous section, has a readily detectable cellular basis. This "cell-heterosis" expresses itself in the form of an increased number of cells per unit fresh weight.

\section{(iii) The nucleus}

(a) Total nuclear protein. The nuclear proteins have been classified by Busch (1965). In addition to the basic proteins located in the chromosomes

TABLE 3

Mean total nuclear protein content (arb. units) in inbred and $F_{2}$ hybrid rye

\begin{tabular}{|c|c|c|c|c|c|c|}
\hline \multicolumn{7}{|c|}{4 days } \\
\hline Replicates & $P_{1}$ & $\mathrm{P}_{8}$ & $P_{18}$ & $\mathrm{P}_{1} \times \mathrm{P}_{8}$ & $\mathrm{P}_{8} \times \mathrm{P}_{18}$ & $\mathrm{P}_{1} \times \mathrm{P}_{13}$ \\
\hline $\begin{array}{l}(a) \\
(b) \\
(c) \\
(d) \\
(e)\end{array}$ & $\begin{array}{r}12 \cdot 08 \\
8 \cdot 86 \\
9 \cdot 48 \\
10 \cdot 69 \\
10 \cdot 00\end{array}$ & $\begin{array}{r}9 \cdot 86 \\
9 \cdot 71 \\
10 \cdot 00 \\
10 \cdot 50 \\
11 \cdot 43\end{array}$ & $\begin{array}{c}12 \cdot 26 \\
12 \cdot 48 \\
= \\
=\end{array}$ & $\begin{array}{c}11 \cdot 8 \\
13 \cdot 14 \\
17 \cdot 26 \\
18 \cdot 14 \\
-\end{array}$ & $\begin{array}{c}18 \cdot 75 \\
15 \cdot 04 \\
= \\
-\end{array}$ & $\begin{array}{l}16 \cdot 16 \\
14 \cdot 88 \\
12 \cdot 50 \\
15 \cdot 52 \\
16 \cdot 04\end{array}$ \\
\hline Mean & $10 \cdot 22$ & $10 \cdot 30$ & $12 \cdot 37$ & $15 \cdot 09$ & $16 \cdot 90$ & $15 \cdot 02$ \\
\hline S.E. $<$ & $1 \cdot 106$ & 0.624 & 0.122 & $2 \cdot 645$ & $1 \cdot 842$ & 1.339 \\
\hline \multicolumn{7}{|c|}{21 days } \\
\hline Replicates & $P_{1}$ & $P_{8}$ & $P_{13}$ & $P_{1} \times P_{8}$ & $P_{1} \times P_{18}$ & $P_{8} \times P_{13}$ \\
\hline $\begin{array}{l}(a) \\
(b) \\
(c) \\
(d) \\
(e)\end{array}$ & $\begin{array}{r}9 \cdot 80 \\
9 \cdot 96 \\
8 \cdot 87 \\
9 \cdot 57 \\
10 \cdot 00\end{array}$ & $\begin{array}{l}8 \cdot 47 \\
8 \cdot 30 \\
8 \cdot 53 \\
9 \cdot 17 \\
9 \cdot 25\end{array}$ & $\begin{array}{c}11 \cdot 00 \\
10.97 \\
= \\
-\end{array}$ & $\begin{array}{c}12 \cdot 20 \\
12 \cdot 46 \\
13 \cdot 83 \\
12 \cdot 90 \\
-\end{array}$ & $\begin{array}{l}13.51 \\
12.34 \\
15.94 \\
15 \cdot 03 \\
11.58\end{array}$ & $\begin{array}{c}12 \cdot 10 \\
12 \cdot 68 \\
11 \cdot 83 \\
- \\
-\end{array}$ \\
\hline Mean & $9 \cdot 64$ & $8.74 \times$ & 10.99 & $12 \cdot 85$ & 13.68 & $12 \cdot 20$ \\
\hline S.E. $<$ & 0.412 & 0.387 & 0.007 & 1.554 & $1 \cdot 622$ & 0.356 \\
\hline
\end{tabular}

there is a large group of acidic nuclear proteins, some of which are in the nuclear sap, and also a number of enzyme systems including the DNA and RNA polymerases. A quantitative assessment of total nuclear protein will therefore give some indication of the extent of variation in the level of nuclear genetic activity in different inbred lines and hybrids.

Measurements of the relative amounts of total nuclear protein were made in the inbred lines $\mathrm{P}_{1}, \mathrm{P}_{8}, \mathrm{P}_{13}$ and the $\mathrm{F}_{2}$ hybrids $\mathrm{P}_{1} \times \mathrm{P}_{13}, \mathrm{P}_{1} \times \mathrm{P}_{8}$ and $\mathrm{P}_{8} \times \mathrm{P}_{13}$. Plants were used at two ages, 4 and 21 days old, but in both cases, and also for the experiments to be described for RNA and histone amounts, young meristems were taken and not those which had been growing as long as the plants themselves. The results for mean amount of total nuclear protein are summarised in table 3. For the 4-day-old plants each replicate consists of an unselected sample of 50 interphase nuclei from a single root of 
one plant. In the 21-day-old material and in all subsequent experiments a sample of 30 interphase nuclei was found to be adequate. Analyses of variance of the two sets of data show significant differences, $\mathrm{P}<0.01$ and $\mathrm{P}<0.001$ respectively, at both ages. That these differences occur specifically between inbred lines and their hybrids is confirmed by comparisons (Dtests) of all meaningful pairwise combinations of lines and hybrids for both sets of data. Results of the analyses are summarised in table 4 . The significant comparisons are $\mathrm{P}_{1} / \mathrm{P}_{1} \times \mathrm{P}_{8}, \mathrm{P}_{1} / \mathrm{P}_{1} \times \mathrm{P}_{13}, \mathrm{P}_{8} / \mathrm{P}_{1} \times \mathrm{P}_{8}, \mathrm{P}_{8} / \mathrm{P}_{8} \times \mathrm{P}_{13}$ for the 4-day-old plants and $\mathrm{P}_{1} / \mathrm{P}_{1} \times \mathrm{P}_{8}, \mathrm{P}_{1} / \mathrm{P}_{1} \times \mathrm{P}_{13}, \mathrm{P}_{8} / \mathrm{P}_{1} \times \mathrm{P}_{8}, \mathrm{P}_{8} / \mathrm{P}_{8} \times \mathrm{P}_{13}$, $\mathrm{P}_{13} / \mathrm{P}_{1} \times \mathrm{P}_{13}$ for the 21-day-old material. The results clearly demonstrate

TABLE 4

Detailed comparisons ( $D$-tests) of differences in mean total nuclear protein amounts in 4-day and 21-day-old inbred and $F_{2}$ hybrid plants

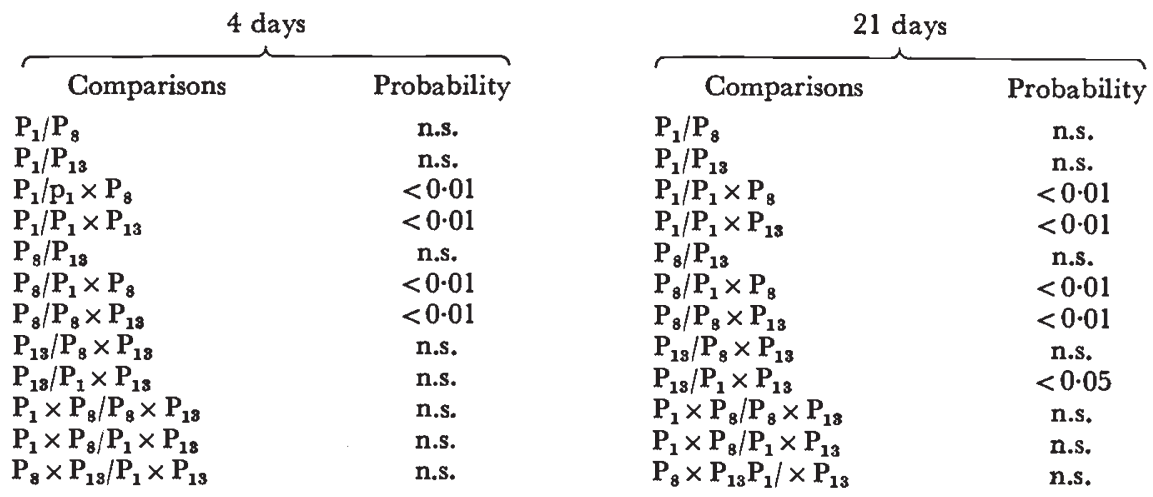

an increase in total nuclear protein production in hybrids as compared with the inbred lines. The consequences of inbreeding and of crossing divergent inbred lines are just as readily observable at the level of the nuclear phenotype as they are for characters of the whole plant. In drawing conclusions about variations in the level of total nuclear protein, care must be taken to demonstrate that the results are not spurious in so far as the mean values in the hybrid material have not been elevated by the presence of extra polyploid nuclei, or by a shift in the relative proportion of $2 \mathrm{C}$ to $4 \mathrm{C}$ nuclei. The distributions as well as the mean values need to be carefully examined. Histograms for the distributions of values are given in figs. 4 and 5. For the purposes of this analysis the values have been grouped in intervals covering two relative units. The histograms show quite clearly that the distributions of values for plants of both ages are similar for lines and hybrids. The change is evidently one of difference in mean due to increase or decrease in amount of protein in all classes of nuclei over the $2 \mathrm{C}-4 \mathrm{G}$ range. Variations in the number of replicates account for the differences in area between some of the histograms.

(b) Nuclear RNA. Quantitative differences in the amounts of total nuclear protein between inbred lines and hybrids gives cause to suppose that a similar pattern of variation could exist at an earlier stage in the sequence of events leading to protein synthesis, namely in amounts of nuclear RNA. The experimental details are similar to those already described for total nuclear protein. Measurements were made on plants at two ages 6 and 
45 days old. The 6-day-old material consisted of the inbred lines $P_{1}$ and $\mathrm{P}_{12}$ and the hybrids $\mathrm{P}_{1} \times \mathrm{P}_{13}$ and $\mathrm{P}_{12} \times \mathrm{P}_{13}$. In the experiment at 45 days of age the inbred line $P_{13}$ was also available. Mean values for relative amounts of total nuclear RNA for both experiments are given in table 5 . There are significant differences between the means $(P<0.05)$ at 6 days and
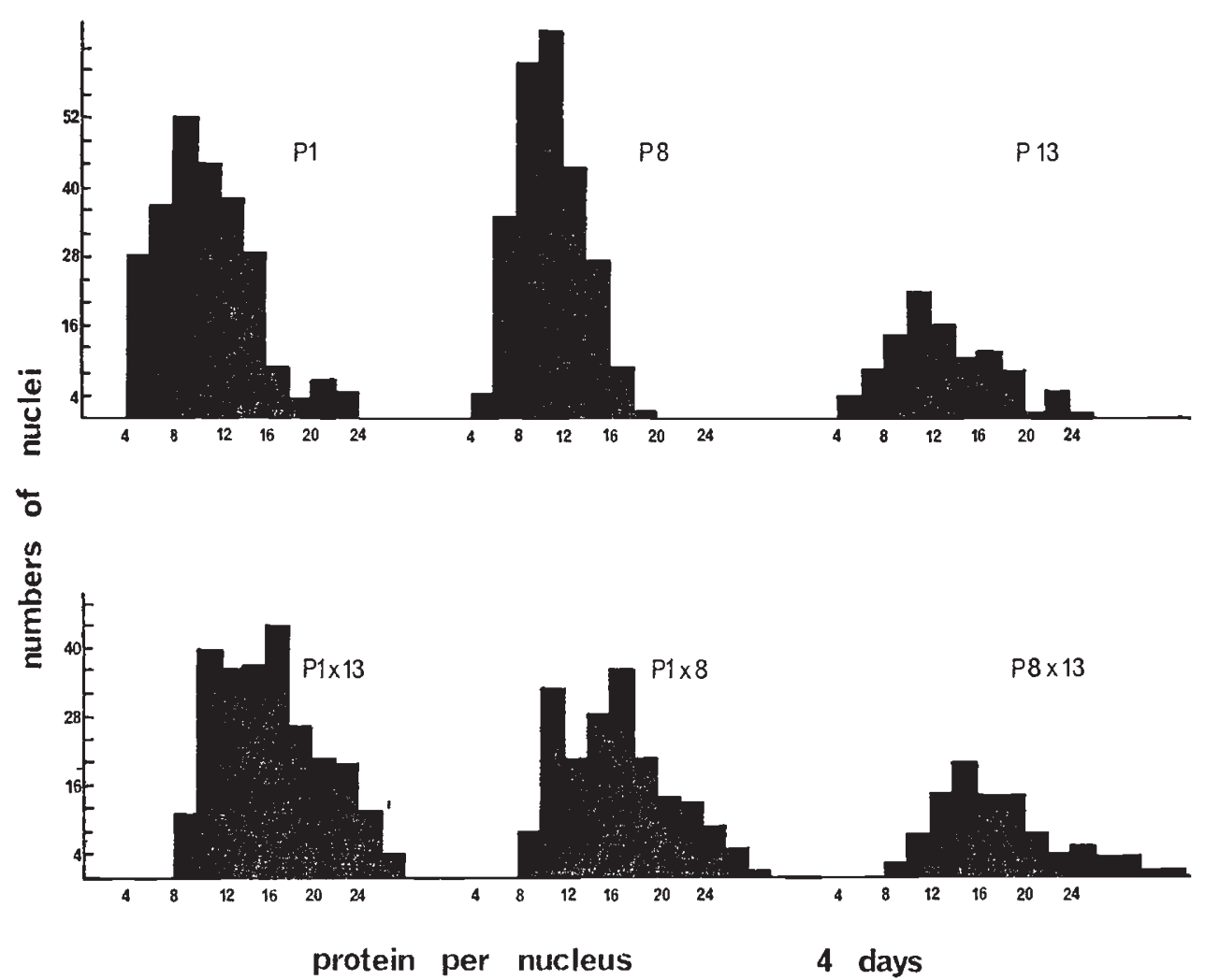

FIG. 4.-Frequency distributions of total nuclear protein amounts in nuclei of 4-day-old inbred lines, $P_{1}, P_{8}, P_{18}$ and their $F_{2}$ hybrids $P_{1} \times P_{13}, P_{1} \times P_{8}$ and $P_{8} \times P_{18}$. Microdensitometer readings (arb. units) pooled from all replicates are grouped in intervals of 2 units. The area under the histogram varies according to the number of replicates.

$(\mathrm{P}<0.001)$ at 45 days. Detailed comparisons of pairwise combinations of lines and hybrids at 6 days old show the only significant difference to be between the inbred $\mathrm{P}_{12}$ and the hybrid $\mathrm{P}_{12} \times \mathrm{P}_{13}$. A more detailed analysis for the 45-day old material is given in table 6 and shows in all cases the hybrids to have a significantly greater amount of nuclear RNA than either of their parental inbred lines. Frequency distributions for RNA amounts, grouped again in intervals of 2 units, are given in figs. 6 and 7 . It is clear that the increase in mean RNA per nucleus in the hybrid material is due to increase in all classes of nuclei, and not to any alteration in the proportions of large and small ones.

(c) Histone amounts. The data presented for total nuclear protein and RNA show quite clearly the consequences of inbreeding depression and of $32 / 3-2 \mathrm{~A}$ 
heterosis to the nuclear phenotype. Hybrids exhibit a clear heterosis for those components of the nucleus which reflect upon the levels of genetic activity and which provide a readily acceptable nuclear basis for the in-
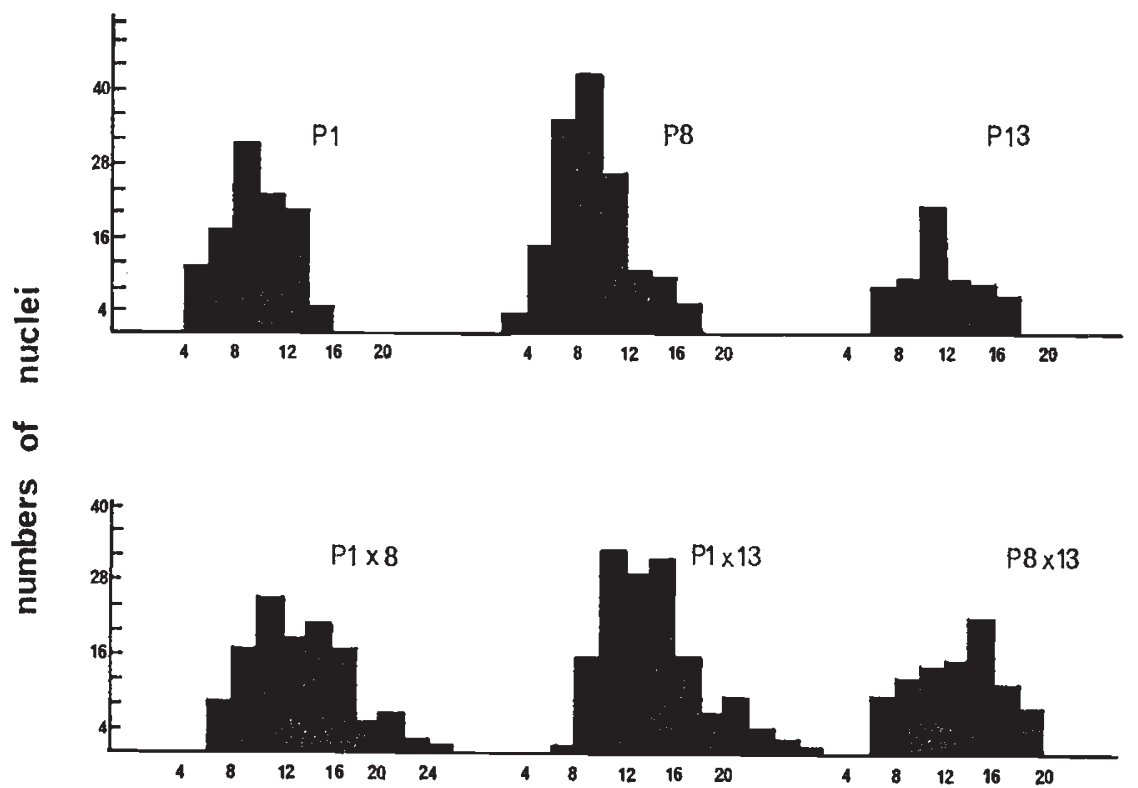

\section{protein per nucleus 21 days}

FIG. 5.-Frequency distributions of total protein amounts in nuclei of 21-day-old inbred lines, $P_{1} P_{8}, P_{18}$ and their $F_{2}$ hybrids $P_{1} \times P_{8}, P_{1} \times P_{13}$. Microdensitometer readings (arb. units) pooled from all replicates are grouped in intervals of 2 units. The area under the histograms varies according to the number of replicates.

TABLE 5

Mean total nuclear RNA content (arb. units) in inbred and $F_{2}$ hybrid rye

\begin{tabular}{ccccc}
\hline \multicolumn{4}{c}{6 days } \\
Replicates & $\mathbf{P}_{\mathbf{1}}$ & $\mathbf{P}_{\mathbf{1 2}}$ & $\mathbf{P}_{\mathbf{1}} \times \mathbf{P}_{\mathbf{1 s}}$ & $\mathbf{P}_{\mathbf{1 2}} \times \mathbf{P}_{\mathbf{1 8}}$ \\
$(a)$ & 16.90 & 16.97 & 18.57 & 19.23 \\
$(b)$ & 14.57 & 14.97 & 20.53 & 20.43 \\
$(c)$ & 17.33 & 16.60 & 18.70 & 25.40 \\
Mean & 16.27 & 16.18 & 19.26 & 21.69 \\
S.E. $<$ & 0.856 & 0.614 & 0.632 & 1.888
\end{tabular}

\begin{tabular}{cccccc}
\hline \multicolumn{7}{c}{45 days } \\
\hline Replicates & $\mathbf{P}_{\mathbf{1}}$ & $\mathbf{P}_{\mathbf{1 2}}$ & $\mathbf{P}_{\mathbf{1 3}}$ & $\mathbf{P}_{\mathbf{1}} \times \mathbf{P}_{\mathbf{1 3}}$ & $\mathbf{P}_{\mathbf{1 2}} \times \mathbf{P}_{\mathbf{1 3}}$ \\
$(a)$ & 21.59 & 20.03 & 16.67 & 21.30 & 21.13 \\
$(b)$ & 19.33 & 19.53 & 17.20 & 26.73 & 23.60 \\
$(c)$ & 17.63 & 19.63 & 18.53 & 22.70 & 24.27 \\
$(d)$ & 18.43 & 16.17 & 18.43 & 25.80 & 22.63 \\
Mean & 19.25 & 18.84 & 17.71 & 24.13 & 22.91 \\
S.E. $<$ & 0.854 & 0.896 & 0.458 & 1.277 & 0.681
\end{tabular}


creased growth and vigour of whole plants. It is not unreasonable to suppose that these quantitative variations in the level of protein and RNA either result from or in turn influence levels of basic histone protein, since it is well established that histones have a role to play in the regulation of gene action

\section{TABLE 6}

Detailed comparisons (D-tests) of differences in mean total nuclear $R N A$ amounts in 45-day-old hybrid and inbred plants

\section{Comparisons Probability}

$\begin{array}{lc}\mathbf{P}_{1} / \mathbf{P}_{13} & \text { n.s. } \\ \mathbf{P}_{1} / \mathbf{P}_{12} & \text { n.s. } \\ \mathbf{P}_{1} / \mathbf{P}_{1} \times \mathbf{P}_{13} & <0.01 \\ \mathbf{P}_{13} / \mathbf{P}_{12} & \text { n.s. } \\ \mathbf{P}_{13} / \mathbf{P}_{1} \times \mathbf{P}_{13} & <0.01 \\ \mathbf{P}_{13} / \mathbf{P}_{12} \times \mathbf{P}_{13} & <0.01 \\ \mathbf{P}_{12} / \mathbf{P}_{12} \times \mathbf{P}_{13} & <0.05\end{array}$
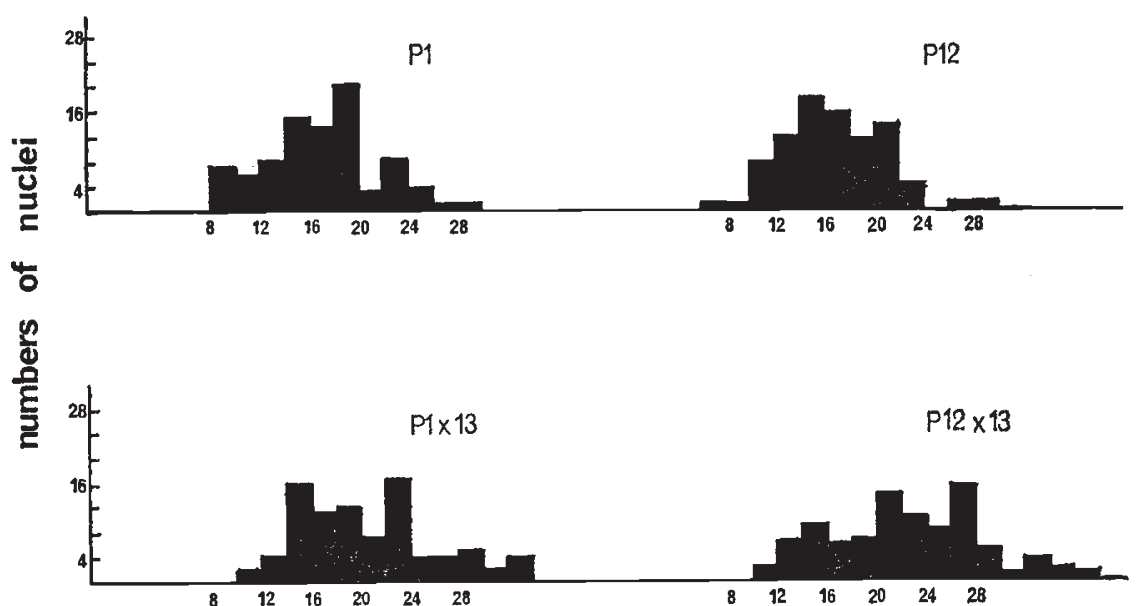

\section{RNA per nucleus 6 days}

FIG. 6.-Frequency distributions of total nuclear RNA amounts in nuclei of 6-day-old inbred lines $P_{1}, P_{12}$ and the $F_{2}$ hybrids $P_{1} \times P_{13}$ and $P_{12} \times P_{13}$. Microdensitometer readings (arb. units) pooled from all replicates are grouped in intervals of 2 units.

in eukaryotes. Measurements of relative amounts of histone per nucleus were made on the lines $\mathrm{P}_{1}, \mathrm{P}_{8}, \mathrm{P}_{13}$ and the hybrids $\mathrm{P}_{1} \times \mathrm{P}_{8}, \mathrm{P}_{8} \times \mathrm{P}_{13}, \mathrm{P}_{1} \times \mathrm{P}_{13}$ at 34 days of age. The data are presented in table 7 , and an analysis of variance shows significant differences $(P<0.01)$ in mean amount of histone per nucleus. The detailed comparisons (D-tests) given in table 8 confirm that these significant differences lie again between certain hybrids and inbred parental lines. Some of the comparisons involving $\mathrm{P}_{13}$ do not give significance, but this is hardly surprising in view of the low number of replicates available for this very weak line. 

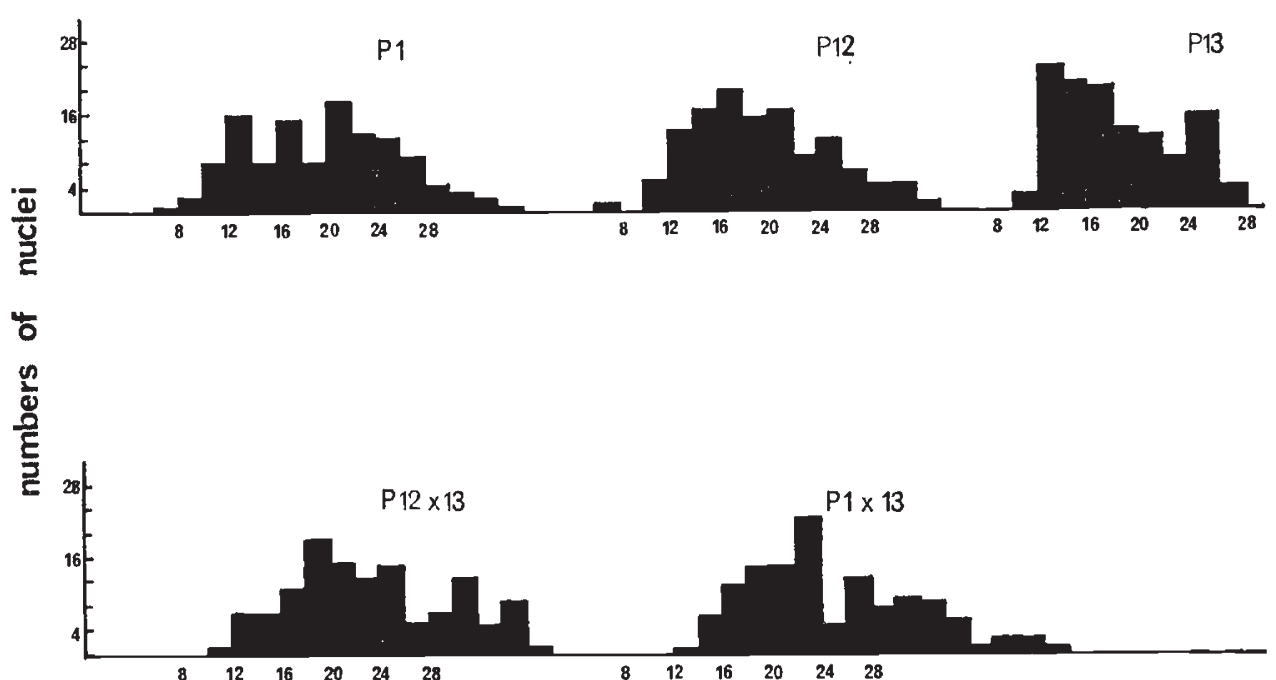

\section{RNA per nucleus $\quad 45$ days}

FIG. 7.-Frequency of total nuclear RNA amounts in nuclei of 45-day-old inbred lines $P_{1}, P_{13}, P_{13}$ and the $F_{2}$ hybrids $P_{12} \times P_{18}$ and $P_{1} \times P_{18}$. Microdensitometer readings (arb. units) pooled from all replicates are grouped in intervals of 2 units.

TABLE 7

Mean total nuclear histone content (arb. units) in 34-day-old inbred $\left(P_{1}, P_{8}\right.$ and $\left.P_{13}\right)$ and $F_{2}$ hybrid $\left(P_{1} \times P_{8}, P_{8} \times P_{18}\right.$ and $\left.P_{1} \times P_{18}\right)$ rye

$\begin{array}{ccccccc}\text { Replicates } & \mathbf{P}_{\mathbf{1}} & \mathbf{P}_{\mathbf{8}} & \mathbf{P}_{\mathbf{1 8}} & \mathbf{P}_{\mathbf{1}} \times \mathbf{P}_{\mathbf{8}} & \mathbf{P}_{\mathbf{8}} \times \mathbf{P}_{\mathbf{1 3}} & \mathbf{P}_{\mathbf{1}} \times \mathbf{P}_{\mathbf{1 3}} \\ (a) & 9.33 & 12.46 & 10.93 & 8.23 & 7.07 & 8.86 \\ (b) & 10.67 & 10.13 & 9.44 & 5.73 & 9.37 & 6.10 \\ (c) & 12.40 & 10.67 & - & 4.83 & - & 7.63 \\ (d) & 11.13 & 9.90 & - & 6.29 & - & 6.93 \\ (e) & 11.83 & 9.43 & - & - & - & 6.56 \\ \text { Mean } & 11.07 & 10.52 & 10.19 & 6.27 & 8.22 & 7.22 \\ \text { S.E. }< & 1.053 & 1.050 & 0.734 & 1.245 & 1.154 & 0.962\end{array}$

TABLE 8

Detailed comparisons ( $D$-tests) of differences in mean total nuclear histone amounts in 34-day-old $F_{2}$ hybrid and inbred plants

Comparisons

$\mathbf{P}_{1} / \mathbf{P}_{8}$

$\mathbf{P}_{1} / \mathbf{P}_{18}$

$\mathbf{P}_{1} / \mathbf{P}_{\mathbf{1}} \times \mathbf{P}_{\mathbf{8}}$

$P_{1} / P_{1} \times P_{13}$

$\mathbf{P}_{8} / \mathbf{P}_{13}$

$\mathbf{P}_{8} / \mathbf{P}_{\mathbf{1}} \times \mathbf{P}_{\mathbf{8}}$

$\mathbf{P}_{8} / \mathbf{P}_{8} \times \mathbf{P}_{13}$

$\mathrm{P}_{18} / \mathrm{P}_{8} \times \mathrm{P}_{18}$

$\mathbf{P}_{18} / \mathbf{P}_{1} \times \mathbf{P}_{13}$

$\mathbf{P}_{1} \times \mathbf{P}_{8} / \mathbf{P}_{8} \times \mathbf{P}_{13}$

$\mathbf{P}_{1} \times \mathbf{P}_{8} / \mathbf{P}_{1} \times \mathbf{P}_{13}$

$\mathrm{P}_{8} \times \mathrm{P}_{13} / \mathrm{P}_{1} \times \mathrm{P}_{13}$
Probability

n.s.

n.s.

$<0.01$

$<0.01$

n.s.

$<0.01$

n.s.

n.s.

n.s.

n.s.

n.s.

n.s. 


\section{Discussion}

The growth analysis results clearly show that the higher fresh weights of the hybrids attained after 60 days of growth are due to two principal causes. Firstly there are differences in the initial " capital " between the hybrid and inbred seeds, the hybrid seed being substantially larger. It is not possible to say, however, which particular component of the seed makes the greatest contribution to this difference in weight. The second factor contributing

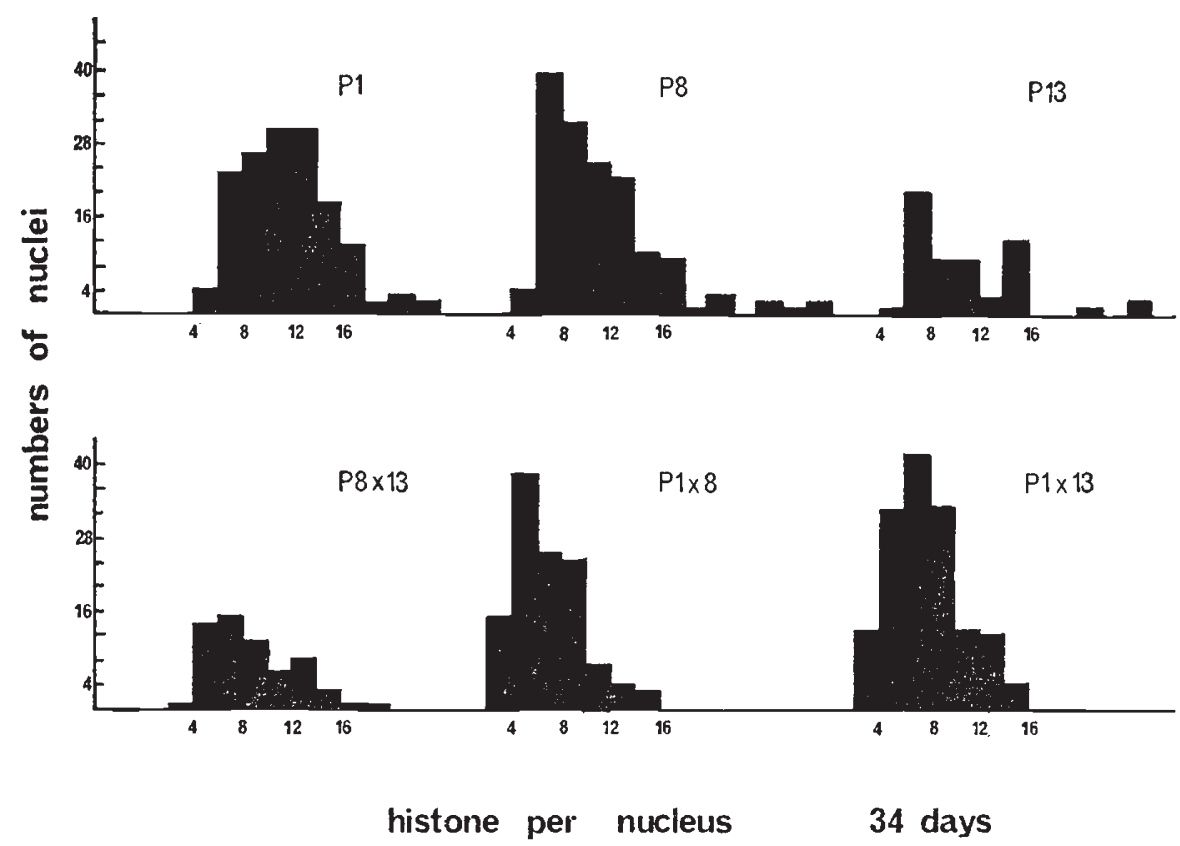

FIG. 8.-Frequency distributions of histone amounts per nucleus in 34-day-old inbred lines $\mathrm{P}_{1}, \mathrm{P}_{8}, \mathrm{P}_{13}$ and their $\mathrm{F}_{2}$ hybrids $\mathrm{P}_{8} \times \mathrm{P}_{13}, \mathrm{P}_{1} \times \mathrm{P}_{8}$ and $\mathrm{P}_{1} \times \mathrm{P}_{13}$. Microdensitometer readings are grouped in intervals of 2 units. The area under the histograms varies according to the number of replicates.

to the difference in absolute fresh weights between inbred and hybrid line is concerned with growth rate. The duration of the exponential growth phase of the hybrids does not extend appreciably beyond those of the inbreds. Except for the case of $\mathrm{P}_{13}$ which is a very weak line the exponential growth phase of both inbreds and hybrids tails off at around 30 days, after which time the Log curves become almost parallel. This is in accord with work on maize by Whaley (1952) who also finds that the growth periods of hybrids are of similar duration to those of the inbreds, and that the relative growth rate of the hybrids and inbreds rarely differ significantly outside the early part of the exponential phase. The development of the hybrid advantage in rye as in maize takes place very rapidly in the early stages of germination and growth.

Examination of the cell number data reveals that at 39 days after germination the almost two-fold increase in fresh weight of the hybrids compared to the inbred lines is paralleled by an almost two-fold increase in the cell number per unit fresh weight of root meristem. It is tempting to 
infer from this that the hybrid meristems are growing and dividing much more rapidly than those of the inbreds. However, it must be borne in mind that inherent structural differences in the organisation of the 3-mm meristematic roots tips used for cell counts in the inbred and hybrid plants may lead to the observed differences, and that these differences need not necessarily reflect an increase in the rate of cell division of the hybrids. The crucial test would be to estimate the mitotic cycle times for both inbred and hybrid plants. Kovalenko (1967) has reported a similar finding for cell number differences in the root cells of hybrid, inbred and open pollinated maize.

At the nuclear level the results show how variation in the nuclear phenotype closely correlates with differences in grow th pattern of different rye genotypes. Changes in the amounts of total nuclear protein and in nuclear RNA confirm our expectations on grounds of modern theories of the transcription and translation of genetic information.

Essentially there was found to be an inversely proportional relationship between total nuclear protein, nuclear RNA and nuclear histone amounts, viz. the hybrids have low nuclear histone and high RNA and total protein contents relative to the high nuclear histone and low RNA and total nuclear protein in the inbred lines. The occurrence of an increase in the nuclear histone as a result of inbreeding depression has already been reported by Polyakova, Narbut and Nalimov (1971). They have demonstrated an increase in the basic protein of the sperm nuclei of inbred radishes as compared to hybrid radish sperm. The inverse proportionality between histone content of chromatin and in RNA synthesis has been shown to exist in several animal and plant species (Huang and Bonner, 1962; Bonner and Huang, 1963; Monesi, 1964; Marushige and Bonner, 1966; Bloch, loc. cit., Paul and Gilmour, 1968) and among these the system which most closely resembles the present one is that involving $B$ chromosome effects in rye. Kirk and Jones (loc. cit.) found that the repression of plant growth and vigour associated with the presence of additional supernumerary B chromosomes was also detectable at the level of the nuclear phenotype. A progressive increase in numbers of $\mathrm{B}$ chromosomes resulted in a progressive decrease in the levels of total nuclear protein and RNA, and an increase in the level of nuclear histone.

Although the means by which the excess histone in the inbred lines could effect a reduction in RNA and protein synthesis can be readily appreciated, viz. a masking of DNA transcription, it is not possible to appreciate how the genetic consequences of inbreeding depression and heterosis relate to a basic mechanism whereby the changes could occur. The question of cause and effect therefore remains elusive, but the results none the less accord in every way with the known effects of inbreeding and heterosis upon the plant phenotype, and offer a crude explanation of how these effects originate and are controlled at the nuclear level.

\section{REFERENCES}

ALFERT, M., AND GESCHWIND, I. I. 1953. A selective staining method for the basic proteins of cell nuclei. Proc. Nat. Acad. Sci., 39, 991-998.

AYONOADU, U. W., AND REES, H. 1971. The effects of B chromosomes on the nuclear phenotype in root meristems of maize. Heredity, 27, 365-383.

BHATTAGHARYA, P. K., NAYLOR, J. M., AND SHAW, M. 1965. Nucleic acid and protein changes in wheat leaf nuclei during rust infection. Science, 148, 1605-1607. 
BLOCH, D. P. 1966. Histone differentiation and nuclear activity. Chromosoma, 19, 317-339. BonNer, J., AND hUANG, R. C. 1963. Properties of chromosomal nucleohistone. $\mathcal{F}$. Molec. Biol., 6, 169-174.

Busch, H. 1965. In Histones and other Nuclear Proteins. Acad. Press Inc.

DIEZ, J. L., AND CIONINI, P. G. 1971. DNA/histone ratio in different regions of polytene chromosomes in the embryo suspensor cells of Phaseolus coccineus. Caryologia, 24, 463-470.

Evans, G. м. 1968. Nuclear changes in flax. Heredity, 23, 25-38.

HIMES, м. 1967. An analysis of heterochromatin in maize root tips. J. Cell Biol., 35, 175-181.

HUANG, R. C., AND BONNER, J. 1962. Histone, a suppressor of chromosomal RNA synthesis. Proc. Nat. Acad. Sci., 48, 1216-1222.

INNOCENTI, A. M. 1971. Cytophotometric determination of histone content in cell nuclei of proliferating and non-proliferating root meristem cells of Triticum durum. Caryologia, $24,457-461$.

JOHN, P. C. L., AND JONES, R. N. 1970. Molecular heterogeneity of soluble proteins and histones in relationship to the presence of B-chromosomes in rye. Exp. Cell Res., 63, $271-276$.

KIRK, D. 1972. Ph.D. thesis, University College of Wales, Aberystwyth.

KIRK, D., AND JONES, R. N. 1970. Nuclear genetic activity in B-chromosome rye in terms of the quantitative interrelationships between nuclear protein, nuclear RNA and histone. Chromosoma, 31, 241-254.

kovalenko, v. F. 1967. Determination of the number of cells in root segments of hybrid, inbred and open-pollinated maize. Trans. Gorski Agric. Inst., 27, 204-208.

KuSANAGI, A., AND YANAGI, T. 1970. Cytochemical determination of changes in nuclear histone content in differentiating root cells of barley and garlic. Protoplasma, 69, 279-282.

LAMM, R. 1936. Cytological studies on inbred rye. Hereditas, 22, 217-240.

MCLEISH, J. 1963. Quantitative relationships between deoxyribonucleic acid and ribonucleic acid in isolated plant nuclei. Proc. Roy. Soc. Lond. B., 158, 261-278.

marushige, K., AND BonNer, J. 1966. Template properties of liver chromatin. J. Molec. Biol. 15, 160-174.

MIKSCHE, J. P. 1968. Quantitative study of intraspecific variation of DNA per cell in Picea glauca and Pinus banksiana. Canad. 7. Genet. Cytol., 10, 590-600.

Mitchel, J. P. 1967. Combined protein and DNA measurements in plant cells using the dinitrofluorobenzene and Feulgen techniques. 7. Roy. Microscop. Soc., 87, 375-381.

MONEsI, v. 1964. Autoradiographic evidence of a nuclear histone synthesis during mouse spermatogenesis in the absence of detectable quantities of nuclear ribonucleic acid. Exp. Cell Res., 36, 683-688.

MOORE, G. P. M. 1971. Cytophotometric studies of nucleic acids and basic proteins during somatic and germinal differentiation of the interstitial cells of Hydra cauliculata (Hyman 1938). Exp. Cell Res., 69, 307-312.

Moss, G. I. 1967. A cytochemical study of DNA, RNA and protein in the developing maize anther. Ann. Bot., 31, 545-553.

MÜNTZING, A., AND AKDIK, s. 1948. Cytological disturbances in the first inbred generation of rye. Hereditas, 34, 485-509.

PAUL, J., AND GILMOUR, R. S. 1968. Organ specific restriction of transcription in mammalian chromatin. 7. Molec. Biol., 34, 305-316.

PIERCE, W. P. 1937. The effect of phosphorus on chromosome and nuclear volume in a violet species. Bull. Torrey Bot. Club, 64, 345-354.

POLYAKOVA, T. F., NARBUT, s. I., AND Nalimov, O. P. 1971. The content of DNA and basic proteins in plant sperm of garden radish inbred lines. Cytol. Genet., 5, 161-170.

ReEs, H. 1955a. Heterosis in chromosome behaviour. Proc. Roy. Soc. B., 144, 150-159.

REES, H. 1955b. Genotypic control of chromosome behaviour in rye. I. Inbred lines. Heredity, 9, 93-116

ROSENKRANTZ, H. S., AND BENDICH, A. 1958. On the nature of the deoxyribonucleic acidmethyl green reaction. 7. Biophys. Biochem. Cytol., 4, 663-664.

SETTERfield, G., SCHREIBer, E., AND WOODWARD, J. 1954. Mitotic frequency determinations and microphotometric Feulgen dye measurements in root tips. Stain Technology, 29, $113-120$.

SYBENGA, J. 1958. Inbreeding effects of rye. Zeits. fur Verebungslehre, 89, 338-354.

WHAleY, w. G. 1952. Physiology of gene action in hybrids. In Heterosis, Ed. J. W. Gowen, pp. 98-113. Iowa State College Press. 